University for Business and Technology in Kosovo

UBT Knowledge Center

Oct 27th, 10:45 AM - 12:15 PM

\title{
Organization of Cognitive Constructionist Memory (OCCM) in using Adverbial subordinators as Cohesive Devices in Essay writing in English
}

Florim Ajdini

University for Business and Technology, florim.ajdini@ubt-uni.net

Follow this and additional works at: https://knowledgecenter.ubt-uni.net/conference

Part of the Education Commons

\section{Recommended Citation}

Ajdini, Florim, "Organization of Cognitive Constructionist Memory (OCCM) in using Adverbial subordinators as Cohesive Devices in Essay writing in English" (2018). UBT International Conference. 130. https://knowledgecenter.ubt-uni.net/conference/2018/all-events/130

This Event is brought to you for free and open access by the Publication and Journals at UBT Knowledge Center. It has been accepted for inclusion in UBT International Conference by an authorized administrator of UBT Knowledge Center. For more information, please contact knowledge.center@ubt-uni.net. 


\title{
Organization of Cognitive Constructionist Memory (OCCM) in using Adverbial subordinators as Cohesive Devices in Essay writing in English
}

\author{
Florim V. Ajdini \\ UBT - Higher Education Institution Str. Lagjia Kalabria p.n., 10000 Prishtinë, \\ Kosovo \\ florim.ajdini@ubt-uni.net
}

\begin{abstract}
Organization of Memory - Introduction In Psychology, the cognitive approach studies the mental processes of people; the organization of memory is a major area of research within this perspective. There are many theories of organization and memory originated from a study performed by Bousefield (1953). All these claim that organization in categories is the natural way to process information in long term memory involving Cognitive Processes as memory call propellers. Modeled after Bousefield's study, the aim of this study is to examine the effects of words' organization on the ability of recalling from memory, when they are stored. It is supposed to give a learning feedback for the English teachers, enabling them to deliver a stronger learning input to their students.
\end{abstract}

Keywords: cognitive, phrasal verbs, essay cohesion, conceptual cognition

\section{Introduction}

English Phrasal verbs have always triggered a variety of difficulties in terms of both, learning and using them in almost all language skills and the overall student communication in English. The fact that this lexical category does not exist officially, in Albanian, it represents a constant barrier towards learning outcomes with these students. The focus of this paper will be put on the use of English Phrasal verbs, in Essay writing, with special focus on the cognitive approach of perception and its impact in writing English essays. The issue to be tackled is their role in terms of setting ground for good, stable and functional essay text wholeness, which must be reached as a result of their appropriate content cognition, seen from the perspective of cognition functionality effect, which as such must decipher the content of these verbs, by ignoring the L1 impact completely (Cornell, A. (1985:221). This approach is supposed to raise the essay productivity in English, making possible for these students to produce better essays, closed to those produced by native speakers of this language. 
In the focus, there will be two target groups (each 50 students). One of these groups is ranging between $\mathrm{B} 1 / \mathrm{B} 2$, while the other between $\mathrm{B} 2 / \mathrm{C} 1$ languages level of the CEFR. In these research terms, there will be used a comparative, qualitative as well as quantitative method of research, which will focus the problem generator as whole, seen from the perspective of traditional learning techniques of English and its use in essay writing. The so called grammar translation method will be on the focus and seen as a learning issue to be replaced by cognition as a learning activity of the language. Cognition will be seen as a process of finding the appropriate equivalents of phrasal verbs in L2, i.e. English, constantly trying to separate the influence of L1 i.e. Albanian in the process. In essay writing, the problem becomes of a complex character especially at the point when students have to deal with the overall essay content control (Cohen, J. 1988:129), where these verbs are of a crucial cohesive relevance to the essay semantics. This can be noticed in all resource texts ( analyzed essays), where in most of the cases the traditional grammar method of learning and using phrasal verbs, proves to derange noticeably the overall essay text engineering, derailing this way the essay controlling idea from the path it should follow to an end. To explain how this situation works in the essay writing practice, the research focus have been put on the content and the semantic functionality of these verbs, in 20 produced essays, involving both target groups, i.e. G1 and G2. Both target groups are 1st year students of English. They are not acquainted with the purpose of the research, so they are left alone for an academic hour to produce one 400-500 word (5 paragraphs in total) essay each. To assure a concise cohesion measurement, an empirical analysis has been used in order to perform as concisely as possible, aiming to detect lower as well as higher cohesion functionality covering the analyzed essays. As the focus of this paper is on phrasal verbs capacity to produce text cohesion, 20 essays in all will be analyzed, to reach this objective.

\section{Questions to tackle (research methods and techniques)}

a) What's the cognitive approach technique towards finding their appropriate equivalent of phrasal verbs in essay writing, without being hampered from the influence of L1?

b) As phrasal verbs are unpredictable and confusing to students, most of the time these words reflect an illogical content and convey a wrong message. This triggers the need for a creating a functional learning and writing routine, to be reached via an enhancement of the cognitive perception of these words. Reaching a higher degree of cognitive operational effectiveness (COE) helps and improves the overall essay cohesiveness as whole.

c) As these words aren't necessarily informal or colloquial; they need to be approached via a 'hypothetic-deductive reasoning', leading towards an easier decipherment of the message they convey in a given sentence. This makes possible a stronger and easier flow of ideas at sentence as well as paragraph level, for the very fact that phrasal verbs not only play a key role in terms of being elements which are seen as idea supporter but they strengthen the essay overall informativity 
as well as essay message transfer. These features, contribute concretely towards strengthening and functionality of the essay's wholeness (Dagut, M., \& Laufer, B. 1985:321). This action has been made possible through an intense cognitive action or an in-depth analysis of the essays in the focus.

\section{Verb quantum in focus}

As the research is of a complex character, in order to make it easier to understand for the reader, below a table of the most frequently used phrasal verbs, in 20 analyzed essays, has been given. Some of them are as follows: to come off $=t \ddot{e}$ $i k$, të largohem; to fall on = të sulmoj, të ndeshem; to fall off= të bie nga, të pikojë $n g a$; to break out= shpërthej; to bear out=të kuptoj, të vërtetohem; to set off= largohem, ik, shkoj; to give over= dorrëzohem, ndërpres; to set out= filloj, nis; run down $=$ përkufizoj, sqaroj shkurt, etc. The overall number of phrasal verbs used in the analyzed essays is approximately 200. Their cognitive deciphering activity by the students has been developed based on three determiners: real, abstract and confuse perception of phrasal verbs. From the practical point of view, these determiners are the ones which indicate the overall reached scale of textual cohesion in the analyzed essays.

In order to facilitate the cognitive decipherment of their meaning, the students' most frequent approach is revealing their meaning which as an activity goes through a set of thinking and cognitive) activities of a constructivist character, before they are filtered to be used in essay writing. This approach is a very complex one, but it has proved that it supports constantly the intensity of productiveness of phrasal verbs, even in moments when students may think they are not needed to be used. The cognitive constructivist approach ( CCA) in essay writing has resulted to be an efficient facilitator which puts on place a wide range of possibilities for using phrasal verbs, departing from the most frequent ones to the rare ones, acquired through learning English, while students are being passively exposed. The technique mostly used is the one focusing the verb as a lexical unit, as content as well as a link it to the verbs known previously. This technique sees the verb as made of two logically contradictory parts, i.e. the particle and the verb basis (Darwin, C. M., \& Gray, L. S. 1999:87), which as such must produce a single meaning content to be fitting appropriately within the logical contextual linking at sentence, paragraph and finally the whole essay cohesiveness.

\section{Analytical part of the research}

The analytical focus in this paper has constantly been put on the way how phrasal verbs have been comprehended and used in the source essays for analysis, how much the cognitive constructivist approach or activity has helped students in terms of their decipherment and what's the degree it has reached in general 
concerning the overall essay cohesiveness. According to Kleinmann, (1977:211), and Schechter, (1974:232), students usually hesitate to use L2 constructivist techniques in cases when they notice that their meaning is different from L1 system, i.e. Albanian. In this regard, 20 phrasal verbs used in the essay have proved to be reduced into 16 ones. This is the case with the Group 1 of students, who based on a previous diagnostic assessment, are qualified as belonging to the $\mathrm{B} 2 / \mathrm{C} 1$ level of language skills of the CEFR. Checked in terms of the semantic complexity the used verbs reveal, 8 of them are qualified as regular ones and the 8 others, are seen as complex ones, which have come into expression to be used in the text, as a result of a deeper thinking of the tested students, generated as a result of an intensive cognitive constructivism, based on Brunner's theory of efficient learning or discovery learning. In this particular research, this approach has been used through discovering or revealing unlearned but acquired phrasal verbs, by which the tested students have solved the so called situations of unfamiliarity of finding the way out of situations where they are required to perform as close as possible to the experiences and the knowledge of the native speaker. Further on, according to Kellerman (1977:67), the hesitation in using English phrasal verbs appears complex, as such it is ongoing and it is present and noticeable in essay writing with these students, is seen to come as a result of the fear of affecting the all wholeness (cohesion) of the essay they are supposed to produce. This happening, would have a huge impact in the overall semantic as well as text grammatical engineering structure (sentence, paragraph). This means that the Group 1 has performed using these techniques with the higher intensity and in a coordinated way, which has shown that the essays produced by them, are characterized of a higher degree of comprehensibility, and as such they are easily understandable by the reader.

The cognitivist approach of deciphering the phrasal verbs, constantly supported by the constructivist thinking, has been performing much better with this respective group. The rate of the essay wholeness functionality (EWF) per essay has reached cca $78 \%$, of the essay wholeness (cohesion). As to the target Group 2 of students, the number of 20 phrasal verbs to be used in the essay, have proved to drop into 9 ones. This group, based on a previous diagnostic assessment, is qualified as belonging to the cca B1/B2 level of the CEFR. Checked in terms of the semantic complexity the used verbs result in a total of 6 , and are qualified as regular frequent ones and the 3 others, are seen as complex and non-frequent ones to the analyzed essays. The density of phrasal verbs used with this group, comes as a result of a superficial thinking of the students, mainly based on formal decipherment of the verb content, avoiding the cognitive approach used with the previous group. It is a slower and inactive cognitive constructivism, which of course comes as a result of their lower language learning achievements. Seen from the perspective of Brunner's theory of efficient learning or learning based on discovery learning attitude (in this particular case), using phrasal verbs results permanently controlled by this rule. On the other hand, the analysis of the database content (all essays), with the focus on the overall essay constructiveness, results to be affected by the grade of functionality of the cognition process of phrasal verbs to be used, which as such is triggered by a lower free contextual approach (LFCA) in moments when they were needed to be used (Dixon, R. 1982:149). The cognitivist approach of deciphering the phrasal verbs, constantly supported by the constructivist thinking, has been 
performing weaker with this respective group. This means that they have performed using this technique rarely and in an irrational and unreasonable basis. The approach intensity makes the essays produced by them, to be characterized of a lower degree of comprehensibility, and as such they are not easily understandable by the reader. The rate of the essay wholeness functionality (EWF) has reached $30 \%$ of the whole essay wholeness (text cohesion).

All these difficulties in one way or another have been influencing the target students at a different scale complexity and as such, as aiming better research outcomes and envisaged expectations for this paper, the use of phrasal verbs in the essay writing by these students is characterized by two distinguished approaches or influences, i.e. the traditional approach of the so called translation grammar way of learning and the other one the cognitivist constructivist comprehending of their message with low degree of influence from the L1, i.e. Albanian.

\section{Research results}

To clarify how this phenomenon has been working out throughout the research analysis carried out during this study, I must put into focus two things. The first one is the concentration and the control on the problem approach and its impact on the written language reproduction, monitoring intensely the scale it affects the overall essay writing cohesiveness and quality. Secondly, focusing the so called double problem orientation approach (DPOA), of treating phrasal verbs from cognitive perspective, emphasizing the lowering of the influence of L1 interference, which is seen through its perspective of overshadowing the essay cohesiveness as whole. The first factor is directly related to the tested students' English language skills, which according to the compared data quantity as well as quality, proves that the first factor has exercised an influence in both tested groups of students involving more than $50 \%$ of the analyzed works i.e. produced essays ( 20 essays). Seen from the empiric point of view, as an appropriate research method to be used, this approach has proved to be very complex and difficult to be implemented in writing with the major part of the tested students, according to their overall language skillfulness in both English as well as in Albanian. The analysis from the database (2x20 essays, with both target groups), focusing the overall essay constructiveness, effected by the functionality of the cognition process of the used phrasal, this process has been seen as a result of the so called free contextual approach of the used quantum phrasal verbs, fitting into the overall meaning of a given paragraph and finally of the essay as a whole textual unit. This cognitivist approach of deciphering the phrasal verbs, constantly supported by the constructivist thinking, has been performing differently with the two groups. Mostly of the phrasal verbs belong to regular frequent ones, which these students have assimilated in class activities while learning or as a result of being passively exposed to the English as foreign language. This means that, given the fact that tested group, according to the language skillfulness belongs to the low intermediate group (G2) of language proficiency, their essays are rated to $50 \%$ of text logical consistency at level of the 
whole text ( 400- 500 words ). These essays embody an average ranging from 3-6-9 phrasal verbs per each item. The total number of used phrasal verbs for this group is 140-200 ones. On the other hand, the case with the other target group (G1), in quantitative as well as qualitative point of view, has performed fairly better, as they approach the use of phrasal verbs imposed as a result of stringer and better functional constructivism, originating from their learning activities (Kamimoto, T., Shimura, A., \& Kellerman, E. 1992:328). This means that the other 50\% of the analyzed works involve a higher quality of phrasal verbs used in their essays. Each analyzed essay includes 8-13-17 phrasal verbs which raises their total to 300-350 ones. As to the quality and the overall logical functionality of the used verbs, it is evident that contrary to the $2^{\text {nd }}$ group, the $1^{\text {st }}$ one has used a mixture of both, frequently as well as more complex phrasal verbs, according to the need of the topic they have treated. This student group performance has realized higher text cohesion compared to the Gr. 2 of student essays. In these circumstances, there has been evidenced the so called avoidance phenomena, which has influenced the overall rate of cohesion of the phrasal verbs per essay in general (Fraser, B. 1976:233). The overall avoidance phenomena compared to the tested groups or essays has shown an evident discrepancy in terms being more reserved for these tested students (Kamimoto \& Kellerman, E. 1977:233). On the other hand, with the $2^{\text {nd }}$ group of students, (the weaker performing ) the situation is much different, consisting of a total ranging between 150 phrasal verbs out of 300-400 expected to be used. In this case too, these figures represent a sufficient indicator which shows that there has been identified the so called avoidance phenomena, with both tested groups. Although Group 1, has used the decipherment of the phrasal verbs content based on an intensive cognitive approach, whenever they were needed to be used, in this case, the L1 interference with G1 reflects low and insignificant tendencies of L1 interference which is not the case with G2 of students, showing concrete interference tendencies of L1, seeing it as a tool to express their ideas in a simpler way based on passive translation from L1.

\section{Discussion and perspectives}

From the overall research carried out, concerning the importance of the phrasal verbs as cohesive devices in terms of reaching higher grade of essay logical wholeness, this paper has come up with some significant conclusions, which can improve the essay text cohesiveness as whole, whenever phrasal verbs are to be used. Given the fact that the research focus has been put on the cognitive perspective of this verb category, the cohesion as a crucial text standard, has proved to be reached in a functional way, as the completed research analysis of the overall phrasal verb quantum used in essay writing, by both target groups i.e. G1 and G2 of high, as well as low-intermediate level of language skills (ranging from B1/B2/G2 and B2/C1/G1 of the CEFRL) varies. In this regard, the students with stronger language speaking skills, (G1), have generally used phrasal verbs by comprehending their content as a 
result of a rather stronger cognitive activity input, needed to reveal precisely their real meaning. Such an approach has shown that this activity, not only makes possible for them to use a larger quantum of these verbs, but it enables them to use more complex phrasal verbs, for which the cognition of the confusing linguistic content, requires cognition as crucial psychological activity in the learning as well as the writing process. On the other hand, G2 or the students belonging to the low-intermediate level of skills, have generally used phrasal verbs by comprehending their form or content that they convey led constantly by a weak cognition activity. This approach has proved that with this group of students, the use of phrasal verbs has shown a low input of cognition and activities related to it, as these students, see these verbs as forms which have complex meaning, different to their "equivalents in Albanian" as L1. With this target group G1, this approach has shown that the stronger use of the cognitive activity, not only makes possible for them to broaden the typology gamma of these verbs to be used, but it enables them to use complex phrasal verbs, as required by the topic they are treating. This is for the fact that the cognition process, towards revealing the full meaning of these verbs for this group is more than clear and free. By revealing their content, i.e. their meaning, (independently from their form), the students with higher language skills (B2/C1 of CEFR, 75\% of them), are managing their use in essay writing, constantly based upon the logical content they convey. Practically this means that they match the verb action in accordance with the essay story content. In this regard, the phrasal verbs used per essay result in an overall abundance and have a proper semantic effect matching the overall essay story. As to the case with the students having lower language skills (B1 of CEFR, $75 \%$ of them), revealing their content, i.e. their use in essay writing, constantly results based upon the form i.e. the signifier, which as such is passively being translated in order to convey their meaning in the essay they are to be used.

Having these data at disposition, as a final conclusion for this paper may be given the fact that Phrasal verbs represent a very important linguistic element in essay writing, which seen from the perspective of a cognitiveconstructivist approach to their meaning, do play a key role in the overall essay wholeness. The higher is the intensity of the cognition activity related to their content decipherment, the higher is the degree of the overall text cohesion of the essay. Given this, the overall degree of the text wholeness with the essays of the G1, reaches $88 \%$, while the case with the G2, reaches barely $55 \%$ from the overall text cohesion of $100 \%$ to be reached with students aiming Exit Language level C2 of the European Portfolio for languages

\section{References}

1. Cornell,A.(1985) Realistic aims in teaching and learning verbs $I R A L, 23$

2. Cohen, J. (1988). Statistical power analysis for the behavioral sciences (2nd ed). Hillsdale, NJ: Lawrence Erlbaum Associates

3. Dagut, M., \& Laufer, B. (1985). Avoidance of phrasal verbs: A case for contrastive analysis. Studies in Second Language Acquisition, 5 
4. Darwin, C. M., \& Gray, L. S. (1999). Going after the phrasal verbs: An alternative approach to classification. TESOL Quarterly, 39

5. Dixon, R. (1982). The grammar of English phrasal verbs. Austrl. J. of L. 2

6. Fraser, B. (1976). The verb-particle combination in English. New York: Academic Press.

7. Kamimoto, T., Shimura, A., \& Kellerman, E. (1992). A second language classic reconsidered the case of Schachter's avoidance. $S$ L Research, 8

8. Kellerman, E. (1977). Towards a characterization of the strategy of transfer in second language learning. Interlanguage Studies Bulletin, 2

9. Kellerman, E. (1983). Now you see it, now you don't. In S. Gass \& L. Selinker (Eds.) 